\title{
Reguladores vegetais e teores endógenos de poliaminas durante o desenvolvimento de taro cultivado in vitro
}

\author{
Plant growth regulators in polyamines endogenous levels during the development of taro cultivated \\ in vitro
}

\author{
Adriana Alice Francisco ${ }^{\mathrm{I}}$ Armando Reis Tavares ${ }^{\mathrm{II}}$ Shoey KanashiroII \\ Paulo Roberto Rodrigues Ramos ${ }^{\mathrm{I}}$ Giuseppina Pace Pereira Lima ${ }^{{ }^{*}}$
}

\section{RESUMO}

Neste trabalho foi investigada a assepsia para obtenção de explantes oriundos de tubérculos e a ação das poliaminas espermidina e espermina exógenas associadas aos reguladores vegetais $A I A$ e $B A$ no desenvolvimento, na tuberização in vitro e nos níveis endógenos de putrescina (Put), espermidina (Spd) e espermina (Spm) de taro (Colocasia esculenta). Plantas crescidas em meio contendo espermidina $e$ espermina mostraram tuberização e a associação dessas poliaminas com AIA e BA induziu aumento do número de brotações. Para o estímulo da rizogênese, não foi necessário o uso de reguladores vegetais. Altos teores de putrescina foram encontrados durante a emissão de brotações, enquanto que altos teores de espermidina foram observados durante a formação de rizomas in vitro.

Palavras-chave: Colocasia esculenta, putrescina, espermidina, espermina, Araceae.

\section{ABSTRACT}

The present research investigated the asepsis for attainment of explants deriving of tubers and the polyamines espermidine and espermine exogenous effects associated with the plant growth regulators NAA and BA on the development and tuberization in vitro and the endogenous levels of putrescine (Put), spermidine (Spd) and spermine (Spm) of taro (Colocasia esculenta). Plants grown in the medium with spermidine and spermine showed tuberization and the association of these polyamines with NAA and BA increases number of shoots. Plant growth regulators were not necessary for root initiation. High levels of endogenous Put were found during the shoot emission, while high levels Spd were observed during in vitro root formation.

Key words: Colocasia esculenta, putrescine, spermidine, spermine, Araceae.

\section{INTRODUÇÃO}

Taro (Colocasia esculenta) é uma importante cultura usada como fonte de amido (tubérculos). Técnicas in vitro são uma alternativa para melhorar o método de produção, mas as taxas de multiplicação e tuberização têm sido geralmente modestas (TAKAGI et al., 1997). Um dos grandes problemas enfrentados durante a micropropagação desta espécie, assim como em outras tuberosas, é a assepsia. Para taro, pesquisas mostram que a obtenção de explantes geralmente é realizada em casa de vegetação e, depois que as brotações são formadas, elas são esterelizadas e inoculadas em meio nutritivo (TAKAGI et al., 1997), no lugar de obtenção de gemas oriundas de tubérculos e inoculadas em meio para obtenção de plantas diretamente, o que resultaria em economia de tempo e reagentes.

A morfogênese in vitro como um evento de regeneração de plântulas pode ser obtida por meio da cultura de embriões, embriogênese somática e organogênese direta ou indireta. Para o taro (Colocasia esculenta (L.) Schott.), a micropropagação pode ocorrer por diversos métodos, desde que as condições de cultivo sejam apropriadas. Assim, NYMAN \& ARDITTI (1984) observaram a ocorrência de estruturas anormais em plantas de taro cultivadas in vitro sob a ação de diferentes reguladores vegetais. YAM et al. (1990; 1991), utilizando meio MS (MURASHIGE \& SKOOG, 1962) contendo metade da concentração dos sais, extrato de rizoma de taro e $5 \mathrm{mg} \mathrm{L}^{-1}$ de ANA (ácido

\footnotetext{
Instituto de Biociências, Universidade Estadual Paulista (UNESP), CP 510, 18618-000, Botucatu, SP, Brasil. E-mail: gpplima@ibb.unesp.br.*Autor para correspondência.

"Seção de Ornamentais, Instituto de Botânica (IBt). Av. Miguel Stéfano, 3687, 04301-902, São Paulo, SP, Brasil.
} 
naftalenoacético) e BA (benziladenina) ou $2 \mathrm{mg} \mathrm{L}^{-1} \mathrm{de}$ 2,4,5-T (ácido 2,4,5-triclorofenoxiacético) também obtiveram calos a partir de gemas axilares.

O desenvolvimento de raízes, a iniciação e o desenvolvimento floral, a frutificação, a tuberização, e a senescência são processos nos quais as poliaminas podem estar envolvidas. Vários modelos sugerem que as poliaminas Spd (espermidina) e Spm (espermina), junto com outros componentes da célula, como as histonas, contribuem com mudanças nas conformações do DNA, promovendo estabilização das duplas hélices, determinando as estruturas secundárias e terciárias do ácido nucléico. Espermidina e espermina, assim como seu precursor, a diamina putrescina, são policátions e estão relacionadas com a regulação da divisão celular, diferenciação e na morfogênese (GALSTON \& KAURSAWHNEY, 1995). As poliaminas, quando adicionadas ao meio de cultura, têm-se mostrado estimuladoras de crescimento em várias plantas (TASSONI et al., 2000). No entanto, apesar de desempenharem papéis positivos em vários sistemas de cultura, em alguns casos mostram-se ineficientes.

Estudos sobre a correlação entre adição de poliaminas e multiplicação in vitro de taro demostraram que as melhores regenerações, em ápices de brotações primárias, eram obtidas tanto em meios suplementados com precursores de Put, arginina e ornitina quanto com Spm (SABAPATHY \& NAIR, 1992). Em batata, MADER (1995) relacionou os efeitos das poliaminas livres e conjugadas com tuberização e constatou que a formação do tubérculo está associada ao aumento dos níveis de Spd e Spm livres na célula.

Neste trabalho foi investigada a melhor assepsia para obtenção de explantes oriundos de tubérculos de taro (Colocasia esculenta) e a ação das poliaminas espermidina e espermina exógenas associadas aos reguladores vegetais AIA e BA no desenvolvimento, na tuberização in vitro e nos níveis endógenos de putrescina (Put), espermidina (Spd) e espermina (Spm).

\section{MATERIAL E MÉTODOS}

Rizomas de taro foram lavados em água corrente, imersos por 15 minutos em solução de fungicida (Benomil - 1,5 $\mathrm{g} \mathrm{L}^{-1}$ ) e armazenados em sacos plásticos pretos à temperatura ambiente. Após 75 dias, as gemas axilares brotadas do rizoma apresentavam aproximadamente $0,5 \mathrm{a} 0,7 \mathrm{~cm}$ de comprimento e foram usadas como explantes, os quais foram removidos dos rizomas em água corrente e mantidos sob agitação por 20 minutos em solução de fungicida (captan $75 \%-2,5 \mathrm{~g}$ $\left.\mathrm{L}^{-1}\right)$. Posteriormente, visando estabelecer o melhor tratamento de desinfestação dos explantes, em condições assépticas (câmara de fluxo laminar), os explantes foram imersos, sob agitação constante, em soluções de hipoclorito de sódio comercial (2 a 2,5\% de cloro ativo) nas concentrações de 10 (60 e 90 minutos), 20 (10, 15, 20, 30 e 60 minutos), 30 (10, 15, 20 e 30 minutos), 40 ( $10,15,20$ e 30 minutos) e $50 \%$ ( 10,15 , 20 e 30 minutos). Terminada a assepsia, os explantes foram lavados três vezes sucessivamente em água destilada autoclavada e inoculados em meio MS, semisólido (agar 5\%) e pH ajustado para 5,8 antes da autoclavagem a $1,5 \mathrm{~atm}$ e $25^{\circ} \mathrm{C}$. As culturas foram mantidas em sala de crescimento com temperatura controlada a $25 \pm 2^{\circ} \mathrm{C}$, fotoperíodo de 16 horas de luz e oito de escuro e intensidade luminosa de aproximadamente $16,2 \mu \mathrm{mol} \mathrm{m} \mathrm{m}^{-2} \mathrm{~s}^{-1}$.

Após dois meses em cultura, as plântulas de taro, obtidas a partir de gemas, apresentavam a formação de rizomas in vitro. Visando ampliar o número de plântulas, cortaram-se os rizomas desenvolvidos in vitro e dois procedimentos foram testados: inoculação em meio MS e MS modificado (MSm) (adição de $10 \mu$ moles L $\mathrm{L}^{-1}$ AIA e $5 \mu$ moles $\mathrm{L}^{-1} \mathrm{BA}$ ). As plântulas tiveram as folhas e raízes removidas e, em seguida, os rizomas ( $1 \mathrm{~cm}$ de comprimento e $0,7 \mathrm{~cm}$ de largura) foram cortados transversalmente, em duas partes e inoculados no meio MS e MSm.

Com as plântulas obtidas durante os testes de assepsia e por meio de sucessivas multiplicações, obteve-se o material para a condução da segunda fase do experimento, em que foram selecionadas 112 plântulas, apresentando, em média, $1,5 \mathrm{~cm}$ de altura. Em condições assépticas, as plântulas passaram por uma toalete (retirada de tecido oxidado), sendo que $2 / 3$ de suas raízes foram eliminadas.

Sete tratamentos foram estabelecidos com o objetivo de avaliar as alterações proporcionadas pelas poliaminas exógenas (Sigma) (mix de espermidina e espermina) durante a fase de formação dos rizomas: T0 - MS; T1 - MSm; T2 - MS + 1mmol L-1 Spm; T3 - MS + $1 \mathrm{mmol} \mathrm{L}-1$ Spd, T4 - MSm + 1mmol L-1 Spm; T5 - MSm + $1 \mathrm{mmol} \mathrm{L}^{-1} \mathrm{Spd} \mathrm{e} \mathrm{T} 6-\mathrm{MSm}+1 \mathrm{mmol} \mathrm{L}^{-1} \mathrm{Spm}+1 \mathrm{mmol} \mathrm{L}^{-1}$ Spd. Os tratamentos utilizados, nesta fase, foram preparados utilizando o meio MS, sem a adição de ágar. As poliaminas e os reguladores foram adicionados ao meio autoclavado utilizando-se unidade filtrante (MILIPORE) estéril e descartável, contendo poros de $0,22 \mu \mathrm{m}$.

Os tratamentos foram constituídos por 16 tubos de ensaio contendo uma plântula, que foram distribuídos de modo casualizado nas prateleiras, em sala de crescimento à temperatura controlada de $25 \pm$ $2{ }^{\circ} \mathrm{C}$, fotoperíodo de 16 horas de luz e oito de escuro e 
intensidade luminosa de aproximadamente $16,2 \mu \mathrm{mol} \mathrm{m} \mathrm{m}^{-2}$ $\mathrm{s}^{-1}$, por um período de 60 dias. No período foram realizadas quatro coletas, com intervalos de 15 dias. Em cada coleta e nos sete tratamentos, quatro plantas foram removidas aleatoriamente, sendo seus tecidos aéreos e subterrâneos lavados em água deionizada, separados e utilizados para avaliação do teor de poliaminas endógenas (putrescina, espermidina e espermina). O delineamento utilizado foi inteiramente casualizado com sete tratamentos (mistura de poliaminas) e quatro repetições, utilizando-se o teste $\mathrm{F}$ ao nível de $5 \%$ de probabilidade. A comparação das médias dos tratamentos foi realizada utilizando-se o teste de Tukey ( $5 \%$ ), com o pacote estatístico SANEST (ZONTA\& MACHADO, 1984).

As análises de poliaminas endógenas foram realizadas de acordo com o método de FLORES \& GALTON (1982), modificado por LIMA et al. (2006). As poliaminas foram quantificadas por espectroscopia de emissão de fluorescência com o programa Software Image Master VDS (Video Documentation System), versão 2.0 da Amersham Pharmacia Biotech 1995, 1996. Os teores de poliaminas livres foram expressos em nmol $\mathrm{g}^{-1}$ matéria fresca.

\section{RESULTADOS E DISCUSSÃO}

Uma das maiores dificuldades para a obtenção de plântulas in vitro reside no fato de obterem-se tecidos descontaminados sem conduzi-los à morte quando isolados (GRATTAPAGLIA \& MACHADO, 1998). Dos procedimentos utilizados para assepsia dos explantes, nenhum foi considerado eficiente, sendo que o menor índice de contaminação foi de $30 \%$, que é uma taxa alta de contaminação para qualquer cultivo in vitro.

As gemas utilizadas como explantes, desenvolvidas dos rizomas, não apresentaram diferencial quanto ao índice de contaminação. Durante os testes de assepsia, de todos os tratamentos testados, o melhor resultado ( $30 \%$ de contaminação) foi alcançado submetendo os explantes a uma solução de hipoclorito de sódio comercial $10 \%$ por 60 minutos. De acordo com GRATTAPAGLIA \& MACHADO (1998), o estado fitossanitário dos tecidos utilizados como explantes, principalmente no que se refere aos microorganismos endógenos, é determinante para o sucesso desta primeira etapa do trabalho. Em taro, vários autores estudaram e identificaram a ocorrência de grande número de fungos parasitas, presentes tanto em tecidos aéreos quanto subterrâneos (OBETA \& OBETA, 1996).

Das duas metodologias testadas para multiplicação in vitro de taro (1- corte dos rizomas desenvolvidos in vitro, com posterior inoculação em meio MS e 2- corte dos rizomas desenvolvidos in vitro, com posterior inoculação em meio MS modificado), foi possível constatar que o melhor procedimento utilizado para a ampliação do número de plantas de taro foi alcançado associando-se o corte dos rizomas desenvolvidos in vitro com a suplementação do meio nutritivo com auxina e citocinina.

O meio MSMm estimulou o desenvolvimento de brotações múltiplas (em média sete brotações/metade de rizoma) aos 15 dias após a inoculação, enquanto que os explantes cultivados em meio MS emitiram, em média, cinco brotações/metade de rizoma inoculado, após 90 dias da data de inoculação, confirmando os resultados obtidos por CARVALHO \& CORDEIRO (1990).

Para o enraizamento das plântulas obtidas in vitro, não foi necessária a utilização ou elaboração de outros meios de cultura, uma vez que as brotações, desenvolvidas nos pedaços de rizoma, quando destacadas e inoculadas em meio MS emitiam e desenvolviam normalmente inúmeras raízes.

Quanto aos teores endógenos de poliaminas livres, observa-se, na tabela 1 , que, durante os sessenta dias do experimento, o desenvolvimento vegetativo dos explantes foi acompanhado por alterações nos teores endógenos de poliaminas. Analisando os teores médios de Put, Spd e Spm obtidos a cada quinze dias em tecidos aéreos, verifica-se que a principal amina sintetizada nestes tecidos foi Put, mesmo em tratamentos com espermidina ou espermina exógena. Estes resultados confirmam os obtidos por HELLEBOID et al. (1995), que constataram que a síntese de poliaminas livres, especialmente Put, aumentava durante a diferenciação e o crescimento dos embriões de chicória (Chicorium sp.).

Para Spd, analisando os níveis médios obtidos durante o experimento, notou-se que, ao comparar primeiramente os tratamentos T0, T2 e T3, não ocorreram diferenças significativas e as plantas mantidas em meio de cultura contendo Spd exógena (T3) apresentaram maiores níveis de Spd endógena. Contudo, na média, foi possível verificar também que a presença de auxina e citocinina no meio de cultura parece ter afetado estes teores, facilitando talvez a formação ou mesmo a absorção da Spd presente no meio, ou ainda, promovendo a síntese dessa amina, uma vez que os maiores teores de Spd endógena foram obtidos em plantas mantidas em meio de cultura que apresentam esse tipo de interação (T5, T1, T6 e T4).

Comparando a média dos tratamentos T0, T2 e T3, as plantas cultivadas em meio suplementado com Spm (T2) apresentaram tecidos aéreos com maiores 
Tabela 1 - Teores endógenos de putrescina, espermidina e espermina ( $\mu$ mols $\mathrm{g}$ de matéria fresca ${ }^{-1}$ ) em tecidos da parte aérea de plantas de taro, mantidas nos diferentes tratamentos. Botucatu, SP. 2007.

\begin{tabular}{|c|c|c|c|c|c|c|c|}
\hline \multicolumn{8}{|c|}{ Meios de cultura } \\
\hline \multicolumn{8}{|c|}{ Putrescina ( $\mu$ mols Put $\mathrm{g}^{-1}$ de matéria fresca) } \\
\hline Dias & MS & MSm & $\mathrm{MS}+\mathrm{Spm}$ & $\mathrm{MS}+\mathrm{Spd}$ & $\mathrm{MSm}+\mathrm{Spm}$ & $\mathrm{MSm}+\mathrm{Spd}$ & $\mathrm{MSm}+\mathrm{Spm}+\mathrm{Spd}$ \\
\hline 15 & $249,1 \mathrm{C}$ & $232,1 \mathrm{C}$ & $442,2 \mathrm{~B}$ & $425,2 \mathrm{~B}$ & 396,7 B & $465,2 \mathrm{~B}$ & $740,5 \mathrm{~A}$ \\
\hline 30 & $565,3 \mathrm{C}$ & $317,1 \mathrm{D}$ & $887,6 \mathrm{AB}$ & $330,9 \mathrm{D}$ & $985,0 \mathrm{~A}$ & $801,3 \mathrm{~B}$ & $610,7 \mathrm{C}$ \\
\hline 45 & $602,2 \mathrm{D}$ & $861,1 \mathrm{~B}$ & $739,3 \mathrm{C}$ & $887,0 \mathrm{~B}$ & $876,9 \mathrm{~B}$ & $763,2 \mathrm{BC}$ & $985,1 \mathrm{~A}$ \\
\hline 60 & $776,8 \mathrm{C}$ & $937,0 \mathrm{~B}$ & $746,9 \mathrm{C}$ & $622,7 \mathrm{D}$ & $655,8 \mathrm{D}$ & $765,2 \mathrm{C}$ & $1442,1 \mathrm{~A}$ \\
\hline Média & $548,3 \mathrm{C}$ & $586,8 \mathrm{C}$ & $704,0 \mathrm{~B}$ & $566,5 \mathrm{C}$ & $729,1 \mathrm{~B}$ & 698,7 B & $944,6 \mathrm{~A}$ \\
\hline $\mathrm{CV}(\%)$ & 17,9 & & & & & & \\
\hline \multicolumn{8}{|c|}{ Espermidina ( $\mu$ mols Spd g ${ }^{-1}$ de matéria fresca) } \\
\hline Dias & MS & $\mathrm{MSm}$ & $\mathrm{MS}+\mathrm{Spm}$ & $\mathrm{MS}+\mathrm{Spd}$ & $\mathrm{MSm}+\mathrm{Spm}$ & $\mathrm{MSm}+\mathrm{Spd}$ & $\mathrm{MSm}+\mathrm{Spm}+\mathrm{Spd}$ \\
\hline 15 & $151,6 \mathrm{C}$ & $211,4 \mathrm{BC}$ & $172,3 \mathrm{C}$ & $177,3 \mathrm{C}$ & $192,0 \mathrm{C}$ & $276,4 \mathrm{~A}$ & $284,1 \mathrm{~A}$ \\
\hline 30 & $98,8 \mathrm{D}$ & $190,1 \mathrm{C}$ & $122,1 \mathrm{D}$ & $153,4 \mathrm{CD}$ & $221,4 \mathrm{BC}$ & $482,3 \mathrm{~A}$ & $283,0 \mathrm{~B}$ \\
\hline 45 & $277,6 \mathrm{C}$ & $380,3 \mathrm{~A}$ & $157,4 \mathrm{D}$ & $311,1 \mathrm{BC}$ & $397,9 \mathrm{~A}$ & $451,6 \mathrm{~A}$ & $245,1 \mathrm{C}$ \\
\hline 60 & $178,1 \mathrm{C}$ & $582,9 \mathrm{~A}$ & $120,5 \mathrm{C}$ & $137,8 \mathrm{C}$ & $439,1 \mathrm{~B}$ & $462,5 \mathrm{~B}$ & $542,5 \mathrm{~A}$ \\
\hline Média & $176,5 \mathrm{C}$ & $341,2 \mathrm{~B}$ & $143,1 \mathrm{C}$ & $194,9 \mathrm{C}$ & $312,6 \mathrm{~B}$ & $418,2 \mathrm{~A}$ & $338,7 \mathrm{~B}$ \\
\hline $\mathrm{CV}(\%)$ & 20,1 & & & & & & \\
\hline \multicolumn{8}{|c|}{ Espermina ( $\mu$ mols $\mathrm{Spm} \mathrm{g}^{-1}$ de matéria fresca) } \\
\hline Dias & MS & MSm & $\mathrm{MS}+\mathrm{Spm}$ & $\mathrm{MS}+\mathrm{Spd}$ & $\mathrm{MSm}+\mathrm{Spm}$ & $\mathrm{MSm}+\mathrm{Spd}$ & $\mathrm{MSm}+\mathrm{Spm}+\mathrm{Spd}$ \\
\hline 15 & $84,0 \mathrm{D}$ & $114,9 \mathrm{D}$ & $365,3 \mathrm{~A}$ & $176,1 \mathrm{C}$ & 294,3 B & 294,3 B & $206,3 \mathrm{C}$ \\
\hline 30 & $87,8 \mathrm{C}$ & $101,7 \mathrm{BC}$ & $95,0 \mathrm{C}$ & $69,7 \mathrm{C}$ & $231,9 \mathrm{~A}$ & $247,1 \mathrm{~A}$ & 143,2 B \\
\hline 45 & $107,2 \mathrm{C}$ & $94,9 \mathrm{C}$ & $165,3 \mathrm{~B}$ & $90,9 \mathrm{C}$ & $212,4 \mathrm{~A}$ & $150,0 \mathrm{~B}$ & $113,0 \mathrm{C}$ \\
\hline 60 & $83,6 \mathrm{D}$ & $284,2 \mathrm{~A}$ & $135,2 \mathrm{C}$ & $69,7 \mathrm{D}$ & $302,9 \mathrm{~A}$ & 220,4 B & 206,5 B \\
\hline Média & $90,6 \mathrm{C}$ & $148,9 \mathrm{~B}$ & 190,2 B & $101,6 \mathrm{C}$ & $260,4 \mathrm{~A}$ & $228,0 \mathrm{~A}$ & $167,3 \mathrm{~B}$ \\
\hline CV $(\%)$ & 16,6 & & & & & & \\
\hline
\end{tabular}

Médias não seguidas das mesmas letras na horizontal diferem entre si significativamente ao nível de $5 \%$ de probabilidade de erro pelo teste de Tukey.

níveis de Spm endógena, enquanto que as plantas cultivadas em meio contendo AIA e BA e Spm (T4) apresentaram maiores teores de Spm endógena, quando comparado com os demais tratamentos, embora estatisticamente não tenha sido evidenciada diferença significativa entre os tratamentos T4 e T5. No entanto, os teores de Spm tenderam a diminuir, sugerindo talvez que, a Spm absorvida do meio nutritivo esteja sendo metabolizada em outras aminas ou em formas conjugadas ou mesmo degradada por enzimas oxidativas, tais como poliaminas oxidases (BOUCHEREAU et al., 1999).

A degradação das poliaminas é um circuito regulatório complexo, capaz de ajustar os níveis de Put, Spd e Spm nas células, as quais são necessárias para a ocorrência de diferentes transformações metabólicas dos tecidos, além de contribuirem também com a adequação dos níveis do nitrogênio solúvel, essenciais durante o desenvolvimento do vegetal (SLOCUM, 1991; MARTIN-TANGUY, 1997). Assim, de acordo com os resultados obtidos nestas análises, conclui-se que, em tecidos aéreos de taro, os altos teores evidenciados principalmente para Put e Spd influenciaram o desenvolvimento das brotações nos explantes mantidos nos tratamentos T4, T5 e T6.

A elevação nos teores de Put está geralmente associada à idade e alongação celular, enquanto que o aumento na síntese de Spd é característico de tecidos meristemáticos (CVIKROVÁ et al., 1998). Na biossíntese das poliaminas, Put é a primeira a ser sintetizada a partir dos aminoácidos ornitina e/ou arginina, sendo catalisadas por Ornitina Descarboxilase (ODC) e Arginina Descarboxilase (ADC), respectivamente. TIBURCIO et al. (1990) sugeriram que o aumento na atividade de ODC geralmente precede a síntese de DNA e divisão celular. A Put livre e conjugada atua em fases específicas do ciclo celular, sendo, portanto, necessária para a replicação do DNA. Dessa forma, as poliaminas têm sido indicadas como atuantes em muitos eventos celulares (TASSONI et al., 2000).

Comparando resultados obtidos em plantas transgênicas e mutantes, WALDEN et al. (1997) concluíram que a morfologia de folhas, o crescimento de raízes e a formação de flores são processos influenciados pelas modificações ocorridas no "pool" de poliaminas endógenas. Resultados semelhantes foram descritos por 
NISHIBORI \& NISHIJIMA (2004). Em tabaco, a auxina e a citocinina aceleram o crescimento dos explantes, ativando a biossíntese de poliaminas nos tecidos, principalmente em períodos anteriores à formação de novos órgãos (TASSONI et al., 2000).

Analisando os teores de Put, Spd e Spm obtidos em tecidos subterrâneos de taro (Tabela 2), constatou-se que tanto o processo de desenvolvimento de raízes quanto a tuberização foram marcados por significativas variações no perfil das poliaminas livres presentes nesses tecidos. Como mencionado anteriormente, muitos parâmetros internos da planta, como características fisiológicas, hormonais, estádios de desenvolvimento, bem como as condições do meio afetaram os teores endógenos das poliaminas (BOCHEREAU et al., 1999).

Os tecidos subterrâneos expostos em solução nutritiva suplementada com reguladores (AIA e BA) e/ou poliaminas apresentam maior síntese de Put quando comparados com os tecidos mantidos no tratamento controle (T0). Observa-se também que a interação entre auxina, citocinina e as poliaminas $\mathrm{Spm}$ (T4), Spd (T5) e a mistura (T6) induziram, em tecidos subterrâneos, grande acúmulo de Put em relação aos demais tratamentos, embora estatisticamente não tenha sido evidenciada diferença significativa entre as médias dos tratamentos T4 e T2.

Em explantes de Solanum sp. cultivados in vitro, PROTACIO \& FLORES (1992) constataram que as poliaminas sintetizadas a partir de ODC participavam dos processos de tuberização e formação de novas brotações, uma vez que tratamentos com difluorometilornitina (DFMO), inibidor da ODC, reduziam ambas as respostas. Para BAJAJ \& RAJAM (1995), a morfogênese, bem como vários outros eventos fisiológicos ocorridos no vegetal, são decorrentes de uma adequação nos níveis endógenos entre Put, Spd e Spm nas células.

Constatou-se que os teores da diamina Put obtidos durante as quatro coletas nos tecidos subterrâneos tenderam a aumentar gradativamente durante o experimento, com exceção apenas para os tratamentos T2 e T3, os quais apresentaram somente elevados níveis de Put no trigésimo dia. Diante dessas evidências, a obtenção de respostas variadas entre os tratamentos, como indução ou não de tuberização, pode

Tabela 2 - Teores endógenos de putrescina, espermidina e espermina ( $\mu$ moles g de matéria fresca ${ }^{-1}$ ) em tecidos subterrâneos de plantas de taro, submetidos a diferentes tratamentos. Botucatu, SP. 2007.

\begin{tabular}{|c|c|c|c|c|c|c|c|}
\hline \multicolumn{8}{|c|}{ Meios de cultura } \\
\hline \multicolumn{8}{|c|}{ Putrescina ( $\mu$ mols Put $\mathrm{g}^{-1}$ de matéria fresca) } \\
\hline Dias & MS & MSm & $\mathrm{MS}+\mathrm{Spm}$ & $\mathrm{MS}+\mathrm{Spd}$ & $\mathrm{MSm}+\mathrm{Spm}$ & $\mathrm{MSm}+\mathrm{Spd}$ & $\mathrm{MSm}+\mathrm{Spm}+\mathrm{Spd}$ \\
\hline 15 & $456,7 \mathrm{C}$ & $524,3 \mathrm{C}$ & $598,4 \mathrm{~B}$ & $631,6 \mathrm{~B}$ & $474,7 \mathrm{C}$ & $789,6 \mathrm{~A}$ & $592,9 \mathrm{~B}$ \\
\hline 30 & $446,9 \mathrm{C}$ & $454,1 \mathrm{C}$ & $727,6 \mathrm{~B}$ & $778,2 \mathrm{~B}$ & $768,9 \mathrm{~B}$ & $722,5 \mathrm{~B}$ & $887,1 \mathrm{~A}$ \\
\hline 45 & $478,0 \mathrm{C}$ & $846,8 \mathrm{~A}$ & $633,6 \mathrm{~B}$ & $580,1 \mathrm{~B}$ & $798,2 \mathrm{~A}$ & $813,7 \mathrm{~A}$ & $834,2 \mathrm{~A}$ \\
\hline 60 & $559,3 \mathrm{D}$ & $416,4 \mathrm{E}$ & $559,4 \mathrm{D}$ & $367,3 \mathrm{E}$ & $680,5 \mathrm{C}$ & $869,8 \mathrm{~B}$ & $1286,1 \mathrm{~A}$ \\
\hline Média & $485,2 \mathrm{E}$ & $560,4 \mathrm{D}$ & $629,7 \mathrm{CD}$ & $589,3 \mathrm{D}$ & $680,6 \mathrm{C}$ & $798,9 \mathrm{~B}$ & $900,1 \mathrm{~A}$ \\
\hline $\mathrm{CV}(\%)$ & 10,5 & & & & & & \\
\hline \multicolumn{8}{|c|}{ Espermidina ( $\mu$ mols Spd g ${ }^{-1}$ de matéria fresca) } \\
\hline Dias & MS & MSm & $\mathrm{MS}+\mathrm{Spm}$ & MS+Spd & $\mathrm{MSm}+\mathrm{Spm}$ & $\mathrm{MSm}+\mathrm{Spd}$ & $\mathrm{MSm}+\mathrm{Spm}+\mathrm{Spd}$ \\
\hline 15 & $154,7 \mathrm{C}$ & $221,5 \mathrm{~B}$ & $259,6 \mathrm{AB}$ & $218,3 \mathrm{~B}$ & $234,7 \mathrm{~B}$ & $305,3 \mathrm{~A}$ & $291,6 \mathrm{~A}$ \\
\hline 30 & $278,5 \mathrm{~B}$ & $209,4 \mathrm{C}$ & $305,3 \mathrm{AB}$ & $338,4 \mathrm{~A}$ & $216,1 \mathrm{C}$ & $213,9 \mathrm{C}$ & $269,7 \mathrm{~B}$ \\
\hline 45 & $283,9 \mathrm{C}$ & $337,8 \mathrm{~B}$ & $500,4 \mathrm{~A}$ & $486,0 \mathrm{~A}$ & $310,0 \mathrm{~B}$ & $364,2 \mathrm{~B}$ & $252,2 \mathrm{C}$ \\
\hline 60 & $253,6 \mathrm{~B}$ & $222,2 \mathrm{C}$ & $149,9 \mathrm{C}$ & $235,7 \mathrm{C}$ & $304,9 \mathrm{~B}$ & $397,0 \mathrm{~A}$ & $406,6 \mathrm{~A}$ \\
\hline Média & $242,7 \mathrm{C}$ & $247,7 \mathrm{~B}$ & $303,8 \mathrm{~B}$ & $319,6 \mathrm{~A}$ & $266,4 \mathrm{~A}$ & $320,1 \mathrm{~A}$ & $305,0 \mathrm{~A}$ \\
\hline CV (\%) & 13,9 & & & & & & \\
\hline \multicolumn{8}{|c|}{ Espermina ( $\mu$ mols Spm g ${ }^{-1}$ de matéria fresca) } \\
\hline Dias & MS & MSm & $\mathrm{MS}+\mathrm{Spm}$ & MS+Spd & $\mathrm{MSm}+\mathrm{Spm}$ & $\mathrm{MSm}+\mathrm{Spd}$ & $\mathrm{MSm}+\mathrm{Spm}+\mathrm{Spd}$ \\
\hline 15 & $131,9 \mathrm{AB}$ & $118,3 \mathrm{~B}$ & $132,8 \mathrm{AB}$ & $63,3 \mathrm{C}$ & 120,5 B & $108,3 \mathrm{~B}$ & $175,7 \mathrm{~A}$ \\
\hline 30 & $115,8 \mathrm{~B}$ & $113,0 \mathrm{~B}$ & $131,4 \mathrm{~B}$ & $149,0 \mathrm{AB}$ & $184,6 \mathrm{~A}$ & $154,8 \mathrm{AB}$ & $197,3 \mathrm{~A}$ \\
\hline 45 & $174,8 \mathrm{~B}$ & $146,7 \mathrm{BC}$ & $387,6 \mathrm{~A}$ & $175,6 \mathrm{~B}$ & $134,2 \mathrm{C}$ & $112,7 \mathrm{C}$ & $143,7 \mathrm{BC}$ \\
\hline 60 & $173,4 \mathrm{AB}$ & $174,1 \mathrm{AB}$ & $228,6 \mathrm{~A}$ & $192,4 \mathrm{~A}$ & $227,0 \mathrm{~A}$ & $159,3 \mathrm{~B}$ & $207,4 \mathrm{~A}$ \\
\hline Média & $149,0 \mathrm{~B}$ & $138,0 \mathrm{~B}$ & $220,1 \mathrm{~A}$ & $145,1 \mathrm{~B}$ & $166,6 \mathrm{AB}$ & $133,8 \mathrm{~B}$ & $181,0 \mathrm{~A}$ \\
\hline CV (\%) & 15,3 & & & & & & \\
\hline
\end{tabular}

Médias não seguidas das mesmas letras na horizontal diferem entre si significativamente ao nível de $5 \%$ de probabilidade de erro pelo teste de Tukey.

Ciência Rural, v.38, n.5, ago, 2008. 
estar relacionada com a síntese de Put em fases específicas do desenvolvimento. Isso sugere um possível envolvimento da Put tanto em eventos relacionados com o desenvolvimento do sistema radicular (tratamentos T0, T1, T4, T5 e T6) quanto na indução da tuberização, verificados em plantas de taro mantidas nos tratamentos T2 e T3.

A influência da Put no enraizamento também foi constatada por TIBURCIO et al. (1989). Eles observaram que a formação de raízes em tabaco foi interrompida em presença de DFMO ou Difluorometilarginina (DFMA), inibidores da síntese de Put. Entretanto, a transferência desses explantes para o meio de cultura contendo poliaminas, levava ao restabelecimento e à capacidade de enraizamento. TARENGHI et al. (1995) relatam que putrescina foi a poliamina predominante nos tecidos em crescimento e em raízes de morango. Por outro lado, a variação entre os teores de Put observada em plantas tuberizadas (T2 e T3) foram semelhantes às constatações verificadas por PELACHO et al. (1994), que observaram a diminuição nos teores da Put em Solanum sp durante a tuberização.

Com relação à influência dos tratamentos nos teores endógenos de Spd e Spm, foi possível constatar que eventos semelhantes verificados nos tecidos aéreos ocorreram em tecidos subterrâneos. Analisando os teores médios obtidos nos sete tratamentos, notou-se que tecidos submetidos aos meios de cultura suplementados com Spd exógena também apresentaram maiores proporções de Spd endógena (tratamentos T3, T5 e T6). Para Spm resultados semelhantes podem ser observados nos tratamentos T2, T4 e T6. Assim, pode-se sugerir que a aplicação exógena de poliaminas supriria as necessidades endógenas, promovendo melhor desenvolvimento e tuberização in vitro de taro, sendo que putrescina teria maior efeito, sendo possivelmente um fator limitante nos dois eventos morfogenéticos.

\section{CONCLUSÕES}

A assepsia do taro foi determinante para o sucesso da técnica e a solução de hipoclorito de sódio comercial $10 \%$ por 60 minutos a mais eficiente. Maiores teores de putrescina ocorreram nos tratamentos com as auxinas e as citocininas nos tecidos aéreos. Não houve influência das poliaminas ou reguladores vegetais no enraizamento. A putrescina pode ser um fator limitante nos eventos morfogenéticos estudados.

\section{REFERÊNCIAS}

BAJAJ, S.; RAJAM, M.V. Efficient plant regeneration from long-term callus cultures of rice by spermidine. Plant Cell Reports, v.14, n.11, p.717-720, 1995.

BOUCHEREAU, A. et al. Polyamines and environmental challenges: recent development. Plant Science, v.140, p.103125,1999 .

CARVALHO, E.F.; CORDEIRO, J.A.D. Um método alternativo e eficiente de propagação vegetativa de inhame (Colocasia esculenta (L.) Schott) e de taioba (Xanthosoma sagittifolium (L.) Schott). Acta Amazononica, v.20, p.11-18, 1990.

CVIKROVÁ, M. et al. Abscisic acid, polyamines and phenolic acids in sessile oak somatic embryos in relation to their conversion potential. Plant Physiology Biochemistry, v.36, n.3, p.247-255, 1998 .

FLORES, H.E.; GALSTON, A.W. Analysis of polyamines in higher plants by high perfomance liquid chromatography. Plant Physiology, v.69, n.3, p.701-706, 1982.

GAlston, A.W.; KAUR-SAWHNEY, R. Polyamines as endogenous growth regulators. In: DAVIES, P.J. (Ed.). Plant hormones physiology, biochemistry and molecular biology. Dordrecht: Kluwer, 1995. p.158-178.

GRATTAPAGLIA, D; MACHADO, M.A. Micropropagação. In: TORRES, A.C. et al. Técnicas e aplicações da cultura de tecidos e de plantas. 2.ed. Brasília: ABCTP/EMBRAPA, 1998. 510p.

HELLEBOID, S. et al. Inhibition of direct somatic embryogenesis by á-difluoromethylarginine in a Cichorium hybrid: effects on polyamine content and protein patterns. Planta, v.196, n.3, p.571-576, 1995.

LIMA, G.P.P. et al. Polyamines contents in some foods from Brazilian population basic diet. Ciência Rural, v.36, p.12941298, 2006.

MADER, J.C. Polyamines in Solanum tuberosum in vitro: free and conjugated polyamines in hormone-induced tuberization. Journal of Plant Physiology, v.146, n.1-2, p.115-120, 1995.

MARTIN-TANGUY, J. Conjugated polyamines and reproductive development: biochemical, molecular and physiological approaches. Plant Physiology, v.100, n.3, p.675-688, 1997.

MURASHIGE, T.S.; SKOOG, F. A revised medium for rapid growth and biossays with tobacco tissue culture. Physiologia Plantarum, v.15, n.3, p.473-497, 1962.

NISHIBORI, N.; NISHIJIMA, T. Changes in polyamines levels during growth of a red-tide causing phytoplankton Chattonella antiqua (Raphidophyaceae). European Journal of Phycology, v.39, n.1, p.51-55, 2004.

NYMAN, L.P.; ARDITTI, J. Effects of 2,3,5-Triiodobenzoic acid on plantlet formation from cultured tissues of taro, Colocasia esculenta (L.) Schott (Araceae). Annals of Botany, v.54, n.4, p.459-466, 1984. 
OBETA, U.J.; OBETA, J.A.N. Fungi associated with storage rots of cocoyams (Colocasia spp.) in Nsukka, Nigeria. Mycopathologia, v.134, n.1, p.21-25, 1996.

PELACHO, M.A. et al. In vitro tuberization of potato: effect of several morphogenic regulators in light and darkness Journal of Plant Physiology, v.144, n.6, p.705-709, 1994.

PROTACIO, C.M.; FLORES, H.E. The role of polyamines in potato tuber formation. In Vitro Cellular and Developmental Biology-plant, v.28, n.6, p.81-86, 1992.

SABAPATHY, S.; NAIR, H. In vitro propagation of taro, with spermine, arginine, and ornithine. I - Plantlet regeneration from primary shoot apices and axillary buds. Plant Cell Reports, v.11, n.5-6, p.290-294, 1992.

SLOCUM, R.D. Polyamine biosyntesis in plants. In: SLOCUM, R.D.; FLORES, H.E. (Eds). Biochemistry and physiology of polyamines in plants. Boca Raton: CRC, 1991. p.23-40.

TAKAGI, H. et al. Cryperservation of in vitro-grown shoot tips of taro (Colocasia esculenta (L.) Schott) by vitrification. 1. Investigation of basic conditions of the vitrification procedure. Plant Cell Reports, v.16, p.594-599, 1997.

TARENGHI, E. et al. Effects of inhibitors of polyamine biosynthesis and of polyamines on strawberry microcutting growth and development. Plant Cell, Tissue and Organ Culture, v.42, n.1, p.47-55, 1995.

TASSONI, A. et al. Polyamine content and metabolism in Arabidopsis thaliana and effect of spermidine on plant development. Plant Physiology and Biochemistry, v.38, n.5, p.383-393, 2000 .

TIBURCIO, A.F. et al. Polyamine metabolism. In: MIFFLIN, B.J. (Ed.). Intermediary nitrogen metabolism: the biochemistry of plants. New York: Academic, 1990. V.16, p.283-325.

WALDEN, R. et al. Polyamines: small molecules triggering pathways in plant growth and development. Plant Physiology, v.113, n.4, p.1009-1013, 1997.

YAM, T.W. et al. Callus growth and plantlet regeneration in taro, Colocasia esculenta var. esculenta (L.) Schott (Araceae) Annals of Botany, v.67, n.4, p.317-323, 1991

YAM, T.W. et al. Plant regeneration in vitro of South Pacific taro, Colocasia esculenta var. esculenta cv. Akalomamale, Aracea. Plant Cell Reports, v.9, n.4, p.229-232, 1990.

ZONTA, E.P.; MACHADO, A.A. SANEST - Sistema de análise estatística para microcomputadores. Registrado na SEI - Secretaria Especial de Informática, sob $\mathrm{n}^{\circ} 066.060$, Categoria A. Pelotas, 1984 